\title{
Building Spreadsheet Skills Using an Interactive Textbook
}

\section{Prof. Matthew W Liberatore, University of Toledo}

Matthew W. Liberatore is a Professor of Chemical Engineering at the University of Toledo. He earned a B.S. degree from the University of Illinois at Chicago and M.S. and Ph.D. degrees from the University of Illinois at Urbana-Champaign, all in chemical engineering. His current research involves the rheology of complex fluids as well as active learning, reverse engineering online videos, and interactive textbooks.

\section{Ms. Katherine Roach, University of Toledo}

Katherine M. Roach is a third year chemical engineering student at the University of Toledo. 


\title{
Building spreadsheet skills using an interactive textbook
}

\begin{abstract}
Performing an Internet search on the term "spreadsheet training" returns over 40,000,000 results. However, most of these training websites include static content or videos demonstrating how to use a certain version of a specific spreadsheet program, usually Microsoft Excel, Google Sheets, or Apple Numbers. Here, a new interactive textbook from zyBooks provides a technology to actively learn how to create and program a spreadsheet. Since many formulas, functions, and features of spreadsheets are common across platforms and versions, spreadsheet concepts can be presented, interacted with inside the interactive textbook, and generally applied in the learner's preferred spreadsheet program. Topics include formulas, functions, charts, trendlines, solver, error, statistics, interpolation, and more. Generally, animations and question sets replace blocks of text used in many textbooks and website. All of the interactions are recorded, and learners are awarded participation and homework grades. Over 100 auto-graded homework problems with randomized numbers and content are being used by students during Spring 2018. Initial findings compiling over 20,000 student interactions include a high reading rate $(90 \%)$ and success on auto-graded homework problems $(87 \%)$ encompassing 8 sections and over 50 problems.
\end{abstract}

\section{Introduction}

In the $20^{\text {th }}$ century, textbooks were a standard technology for higher education and engineering education. In the $21^{\text {st }}$ century, personalized electronics, such as smart phones and laptops, are used at a much higher rate than almost any other resources, including textbooks, by digitally native students. Similarly, very little information is available about textbook usage, and most research shows a majority of college students do not read textbooks [1-6]. However, technology from reading quizzes to interactive textbooks are beginning to measure positive results related to out of class reading and participation [7-15]. Specifically, fully interactive textbooks from zyBooks has shown excellent results helping students in the lower third of the course as well as reading rates as high as $93 \%$ on average for a class of 88 students [7-10, 16-18].

On one hand, textbook prices grew significantly faster than inflation and even slightly faster than college tuition in the last 20 years [19]. On the other hand, multifunctional portable electronics became relatively inexpensive and provide almost instant and mostly free access to factual information. Therefore, students can use the Internet rather than buy textbooks [20]. More modestly priced electronic resources, such as the zyBooks, provide another alternative between traditional textbooks and unfiltered Internet searches.

Spreadsheets are ubiquitous programs used by engineers, accountants, and many other professionals to organize, calculate, and plot. Spreadsheets have been used for more than three decades since the growth of personal computing, and their general usefulness has led to many competing products. Spreadsheets, word processors, and other office programs have thus become commodities. An analogy between spreadsheets and gasoline for automobiles can be constructed as pulling into most gas stations gives a similar setting and product that keeps a vehicle running; most spreadsheets perform the same tasks using the same keystrokes and commands (Figure 1). 


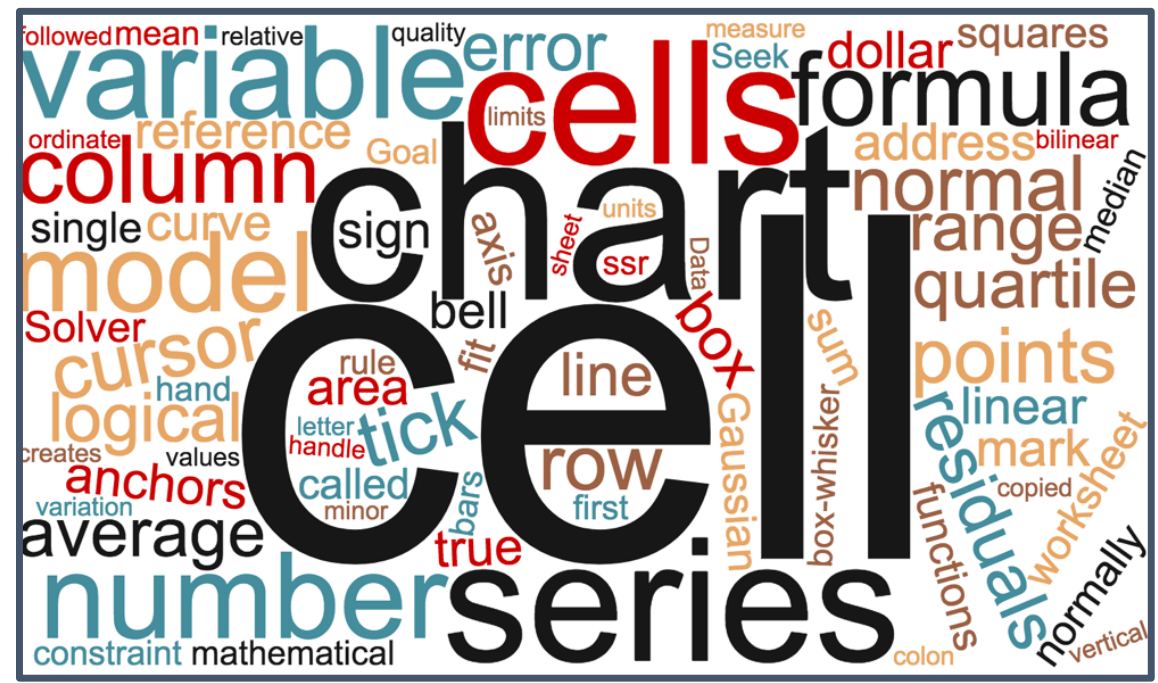

Figure 1. Word cloud of terms related to spreadsheets based on several sections of the zyBook.

Since spreadsheets are a commodity, spreadsheet education and training are also widely available. A simple web search leads to many online resources, many free of charge usually from embedded ads, as well as opportunities for synchronous online courses or in-person workshops, short courses, or boot camps. However, almost all spreadsheet courses and resources are demonstrative with an expert using screenshots or movies to show a student how to use certain features of a spreadsheet. While watching great athletes or musicians is enjoyable, simply observing leads to little learning compared to active participation.

Active learning encompasses techniques that continue to show in single studies and meta-analyses that students learn more through doing [15, 21-23]. Interactivity in an online platform can create learning by doing opportunities [8, 10] while leveraging the strengths of digital natives [24, 25]. Therefore, an interactive textbook for teaching spreadsheets will be introduced here. Interactive features are introduced first, followed by reading and analyzed usage data, and finally conclusions.

\section{Materials: An interactive textbook with spreadsheets}

Less text, more action ${ }^{\mathrm{TM}}$ summarizes the philosophy of interactive materials created by zyBooks, which is a company started in 2012 by computer science faculty. Specifically, full-scale textbook replacements are viewed, read, and interacted with in any HTML5 compliant web browser (without additional plug-ins or software). The lead author created a Material and Energy Balances zyBook, available since January 2016, that has been expanded to include a new chapter on spreadsheets in 2018 as well as some additional spreadsheet content to help students solve material and energy balance problems. During the Spring 2018 semester, $\sim 100$ students were assigned reading and auto-graded homework for 12 sections related to spreadsheets (Table 1). Students paid less than $\$ 60$ to access to both the material and energy balances and spreadsheet content for the semester and can re-subscribe for a fee $(<\$ 20)$ in future annual increments. 
Table 1. zyBook's spreadsheet section titles as of February 2018.

\begin{tabular}{|l|}
\hline Title \\
\hline Spreadsheet basics \\
\hline Spreadsheet formulas \\
\hline Spreadsheet functions \\
\hline Functions: Math and trigonometry \\
\hline Functions: Logical \\
\hline Sort and filter \\
\hline Creating a chart \\
\hline Trendlines \\
\hline Solvers \\
\hline Calculating error and basic statistics \\
\hline Interpolation \\
\hline Integration and numerical integration \\
\hline
\end{tabular}

Fully interactivity allows both student and instructor to observe progress in real time. Clicks record reading tasks including steps through an animation as well as question sets that provide practice without penalty (Table 2). Additionally, success on challenge activities, which are auto-graded homework problems, are available to both student and instructor. Additional data related to question attempts are also recorded.

Table 2. Features of zyBook's spreadsheet content as of February 2018.

\begin{tabular}{|l|c|}
\hline Feature & Number \\
\hline Sections with content & 12 \\
\hline Animations & $40+$ \\
\hline Clicks to 'read' & $200+$ \\
\hline Auto-graded challenge problems & $100+$ \\
\hline
\end{tabular}

The goal of each section or subsection of the zyBooks is to define, demonstrate, practice, and challenge, which will be discussed below. Three features distinguishing zyBooks content are: learning questions, animations, and challenge activities. These features create incremental units, or chunks, for learners to read and interact with, which is consistent with cognitive load theory. In brief, cognitive load theory [21, 26-28] assumes that working memory has a limited capacity when dealing with new learning. Also, the theory presumes partially independent subcomponents of working memory related to different senses, e.g., vision, which are triggered when using the interactive web book. Other theories related to zyBooks' format have been discussed previously [16-18].

\section{Defining new concepts}

Content in each section and subsection normally begins with definitions of new terms and concepts. For spreadsheets, many new concepts are built-in functions that speed calculations. Tables are used to efficiency provide both definitions and a simple example to introduce the new functions (Figure 2). All defined terms are indexed and searchable. Following definitions, animations and learning questions provide interactive elaborations that demonstrate and practice with the new concepts. 
Table 9.3.2: Example spreadsheet functions.

\begin{tabular}{|l|l|}
\hline \multicolumn{1}{|c|}{ Function } & Example \\
\hline $\begin{array}{l}\text { SUM(cell group) is a spreadsheet function that adds the numerical } \\
\text { values of all selected cells. }\end{array}$ & $=$ SUM(A1:A5) adds the numbers in cells A1 to A5. \\
\hline $\begin{array}{l}\text { MAX(cell group) is a spreadsheet function that returns the largest } \\
\text { number from the selected cells. }\end{array}$ & $\begin{array}{l}\text { D1. } \\
\text { DAX(B1:D1) identifies the largest number of Cells B1, C1, or }\end{array}$ \\
\hline $\begin{array}{l}\text { MIN(cell group) is a spreadsheet function that returns the smallest } \\
\text { number from the selected cells. }\end{array}$ & $=$ MIN(B3:B5) finds the smallest number of Cells B3 to B5.
\end{tabular}

Figure 2. Screenshot of a table from spreadsheet functions section that defines terms (bold) and gives an example.

\section{$\underline{\text { Animations }}$}

Animations replace most figures in a zyBook. Animations provide an obvious place where cognitive load theory guides authoring the textbook; each step of an animation is a chunk of information. Building figures and equations using animations takes 30 seconds to 2 minutes to watch 3 to 6 steps, which agrees with human's attention span observed from billions of video views [29]. Entering a formula including a function includes the first two animation steps; elaboration on the parts of a formula as well as distinguishing between stored content and displayed content provide two additional steps in one animation (Figure 3). Screenshots only capture the final frame of each animation step, so cursor movement, clicks, and text input, i.e., all of the motions, are lost when presenting screenshots. 


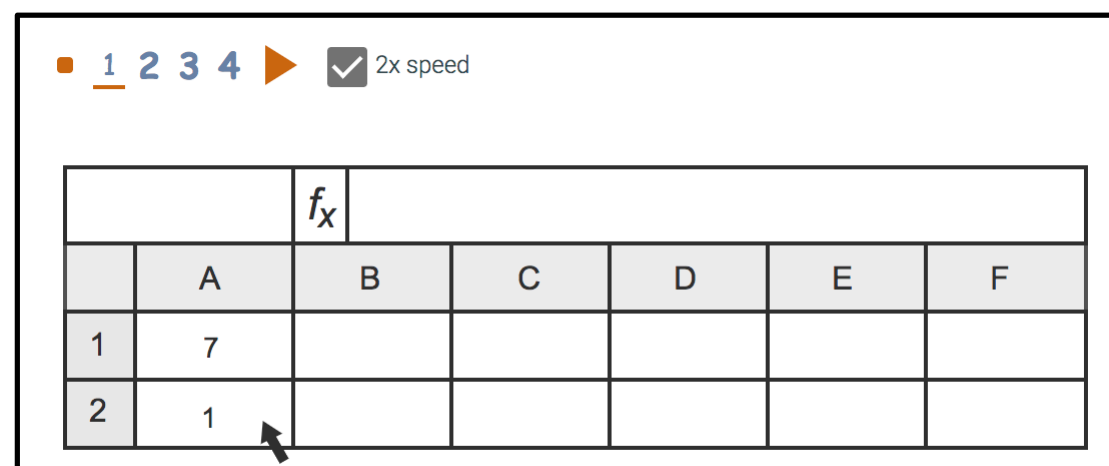

Two cells are filled in with numbers for further analysis using a function.

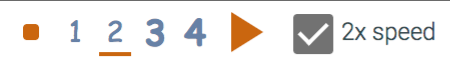

\begin{tabular}{|c|c|c|c|c|c|c|}
\hline \multicolumn{2}{|c|}{ B2 } & \multicolumn{2}{l|}{$f_{X}=\operatorname{SUM}(\mathrm{A} 2: \mathrm{A} 1)$} \\
\hline & A & B & C & D & E & F \\
\hline 1 & 7 & & & & & \\
\hline 2 & 1 & 8 & & & & \\
\hline
\end{tabular}

Numbers or formulas can be the contents of a cell. Clicking on a cell with the desired information includes the cell's contents in a formula.

\begin{tabular}{|c|c|c|c|c|c|c|}
\hline 1234 & \multicolumn{1}{l|}{ 2x speed } \\
\hline \multicolumn{2}{|c|}{ B2 } & $f_{X}$ & $=$ SUM(A2:A1) & \\
\hline & $\mathrm{A}$ & $\mathrm{B}$ & $\mathrm{C}$ & $\mathrm{D}$ & $\mathrm{E}$ & $\mathrm{F}$ \\
\hline 1 & 7 & & & & & \\
\hline 2 & 1 & 8 & & & & \\
\hline
\end{tabular}

A formula with a function has 3 parts: equal sign (=), function (SUM) calls a builtin operation, and argument (A2:A1), which is a cell range here.

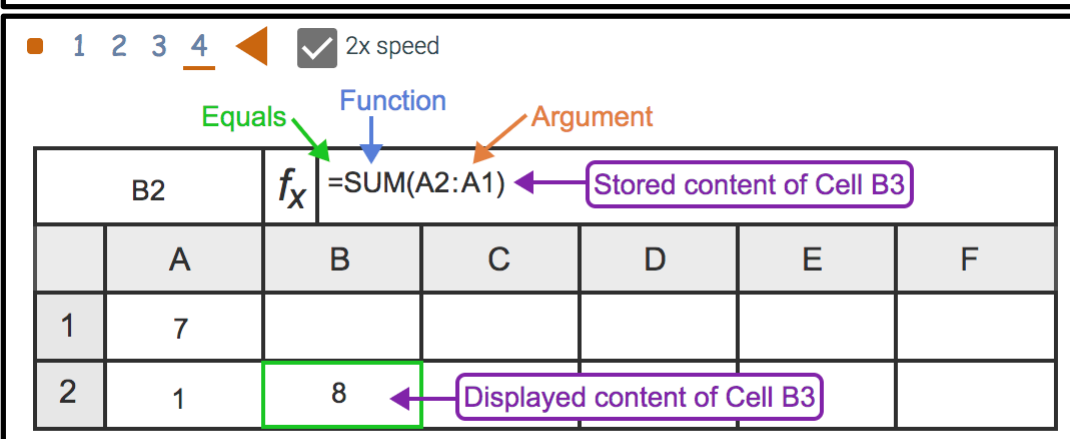

Therefore, Cell B2 has different displayed content and stored content.

Figure 3. Example animation defining spreadsheet functions as well as stored and displayed content. Movement (e.g., cursor movement, typing) is lost within static screenshots. 


\section{Learning questions}

Following many animations, learning questions provide practice in applying new concepts. Learning questions vary between multiple choice, matching, true and false, and short answer questions. Each interaction leads to instantaneous, instructive, and unique feedback. On one hand, correct answers provide an elaboration; on the other hand, incorrect responses detail how to come to an incorrect answer and suggest a path to the correct answer.

Scaffolding is another proven learning strategy engineered into the web book [15]. Learning questions, and challenge activities discussed next, are scaffolded within a set, so simpler queries precede more difficult questions. Alternatively, a matching exercise asks several questions at once; Figure 4 applies knowledge of cell lists and cell groups, which were defined earlier in this section of the web book.

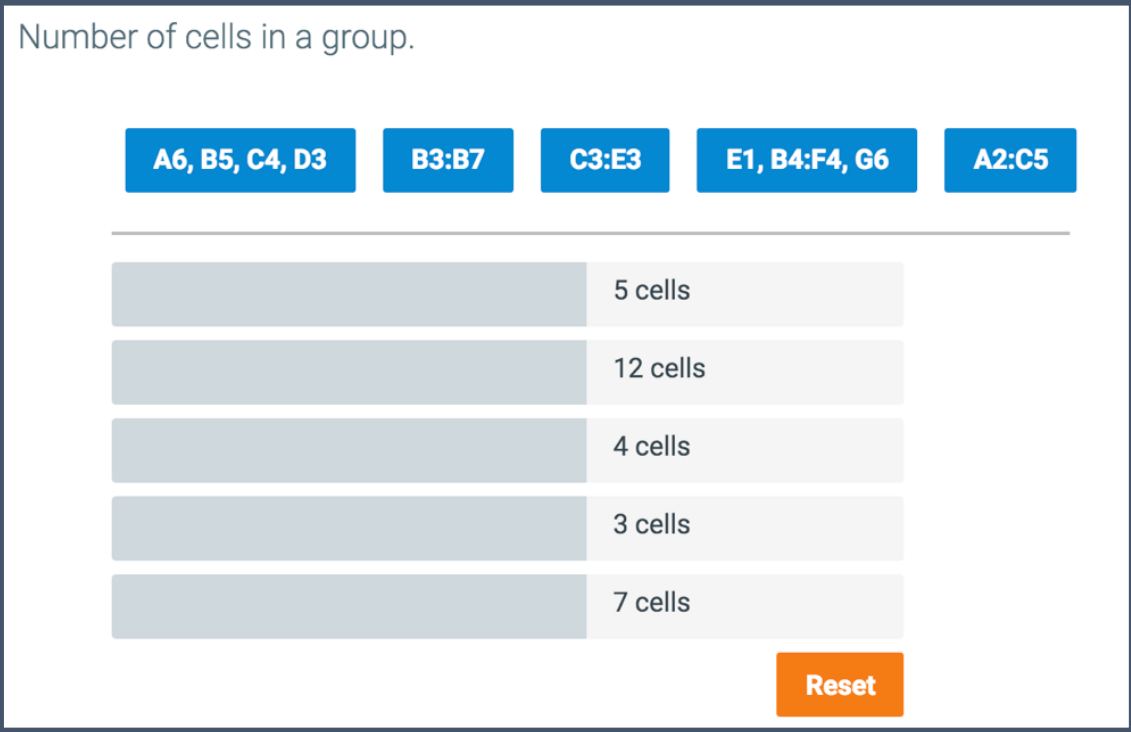

Figure 4. Screenshot of a matching exercise allowing students to practice with the concepts of cell lists and cell groups.

\section{Challenge activities}

Challenge activities test students' learning without penalties for incorrect attempts. As a form of online homework, students are graded for completion of each level of a challenge activity, which varies from 3 to 7 questions of increasing difficulty. The questions are individualized with both rolling numbers and some randomized question content (Figure 5). For example, changing the cell location containing a number to be used in a spreadsheet formula provides the same level of difficulty while requiring concentration and conceptual understanding during each attempt.

The percent correct in each section is transparent to student and instructor, while the number of attempts before correct and total attempts will be presented also in the talk as data is being collected during the Spring 2018 semester. Attempts data from challenge activities related to material and energy balances content are being presented in another ASEE paper this year. 


\begin{tabular}{|c|c|c|c|c|c|}
\hline \multicolumn{6}{|c|}{$\begin{array}{l}\text { In cell E1, report the number of cells containing a numerical value. Hint: Copying the given } \\
\text { values into a spreadsheet may speed up calculations. }\end{array}$} \\
\hline & A & B & C & D & E \\
\hline 1 & 54 & 33 & 24 & 52 & Ex:11 \\
\hline 2 & 35 & 75 & 62 & 63 & \\
\hline 3 & 22 & 25 & 16 & 48 & \\
\hline 4 & 65 & 17 & 28 & 87 & \\
\hline 5 & 93 & 65 & 61 & 49 & \\
\hline 6 & & 96 & & 93 & \\
\hline 7 & & 35 & & 51 & \\
\hline 8 & & 77 & & 97 & \\
\hline \multicolumn{6}{|l|}{9} \\
\hline 10 & & & & & \\
\hline \multicolumn{6}{|c|}{$\begin{array}{l}\text { In cell E1, report the number of cells containing a numerical value. Hint: Copying the given } \\
\text { values into a spreadsheet may speed up calculations. }\end{array}$} \\
\hline & A & B & C & D & E \\
\hline 1 & 83 & 97 & 31 & 33 & Ex:11 \\
\hline 2 & 79 & 88 & 73 & 64 & \\
\hline 3 & 33 & 12 & 73 & 61 & \\
\hline 4 & 17 & 99 & 70 & 16 & \\
\hline 5 & 66 & 95 & 49 & 11 & \\
\hline 6 & 62 & 43 & 52 & 35 & \\
\hline 7 & 33 & 13 & 18 & 34 & \\
\hline 8 & 86 & & 58 & 41 & \\
\hline 9 & 65 & & 74 & 84 & \\
\hline 10 & & & 72 & & \\
\hline
\end{tabular}

Figure 5. Two examples of a single challenge activity question. The number of cells containing a number is different with each attempt. Greater than 20 different possible answers are auto-graded for this problem.

\section{Results and discussion}

Data generated within the Material and Energy Balances zyBook, and specifically the Spreadsheet sections, occurred at University of Toledo during Spring semester 2018. The course consisted primarily of freshman students majoring in chemical engineering and environmental engineering. Enrollment was approximately 100 students with approximately $60 \%$ male and $40 \%$ female.

$\underline{\text { Reading data }}$

Students' clicks are recorded as a reading grade for several sections each week. Only reading participation completed before the due date are reported here. A reading grade accounted for 5\% of the total course grade, since previous work showed small grade incentives lead to high reading 
rates $[9,16,17]$. Almost all clicks create a response, and clicking incorrect responses do not penalize students.

With 12 sections dedicated to spreadsheets, a large amount of reading data is being generated. Reading data for the first eight sections were collected in February 2018 (Table 3). In total, over 18,000 data points were collected that quantify student interactions or clicks. While average reading rates with standard deviations work best for normal distributions, group of students rarely fit this type of scatter. Therefore, median, $1^{\text {st }}$ quartile, and $3^{\text {rd }}$ quartile scores provided more insight into the students' usage. Further analysis will correlate reading with other metrics, including boxwhisker plots, and will be included the talk.

Analyzing the reading participation starts with examining the average reading rate across the entire class, which varied from 90 to $92 \%$. However, the average reading participation is not representative of the distribution across the class. For all 8 sections, the $1^{\text {st }}$ quartile, median, and $3^{\text {rd }}$ quartile scores are all $100 \%$. Therefore, only the bottom $25 \%$ of the class for reading participation pulls the average reading rate down from 100\%. An average reading rate around $90 \%$ is in line with previous work $[16,17]$.

Table 3. Reading participation for eight sections in 2018. $\mathrm{n}=103$ students.

\begin{tabular}{|l|c|c|c|c|c|}
\hline Section title & Clicks & Average & Median & $\begin{array}{c}\text { 1st } \\
\text { quartile }\end{array}$ & $\begin{array}{c}\text { 3rd } \\
\text { quartile }\end{array}$ \\
\hline Spreadsheet basics & 19 & 92 & 100 & 100 & 100 \\
\hline Spreadsheet formulas & 28 & 91 & 100 & 100 & 100 \\
\hline Spreadsheet functions & 13 & 91 & 100 & 100 & 100 \\
\hline Functions: Math and trigonometry & 28 & 92 & 100 & 100 & 100 \\
\hline Functions: Logical & 8 & 90 & 100 & 100 & 100 \\
\hline Sort and filter & 25 & 90 & 100 & 100 & 100 \\
\hline Creating a chart & 35 & 90 & 100 & 100 & 100 \\
\hline Trendlines & 19 & 90 & 100 & 100 & 100 \\
\hline
\end{tabular}

Challenge activity data

Challenge activities include a series of progressively more difficult questions, usually between 3 and 6 per activity. The talk will include students' success in completing over 100 different questions. Additionally, the number of attempts before correct and total attempts will be quantified and analyzed. Results from the first eight sections and 56 different question levels (Table 3) aggregate over $\underline{5,000 \text { student responses }}$ and provide some interesting information on the spreadsheet skills of the students.

The class's average success on challenge activity questions varied from 88 to $90 \%$ for introductory material (i.e., basics, formulas, and functions), while more detailed topics returned 84 to $87 \%$ correct on average for the class. As seen with reading participation, $1^{\text {st }}$ quartile, median, and $3^{\text {rd }}$ quartile scores are all $100 \%$ in all 8 sections. While reading participation is simply effort of clicking without penalty, challenge activity questions must be answered correctly. Answer types vary from a number produced by a spreadsheet formula to the correct spreadsheet formula including syntax and cell ranges. In general, digitally native students are likely exposed to spreadsheets in high school or earlier, which is a significant shift from previous generations of students (including the lead author). Also, most of the students received spreadsheet instruction 
during the previous semester, so high success rates demonstrate an accumulation of spreadsheet skills.

Of note, the lowest average on spreadsheet challenge activities was in the math and trigonometry functions section. Three sets of questions lead to varied success. The first activity related to math functions (e.g, SUM, PRODUCT, QUOTIENT, SQRT) found students earning 88\% across three question levels, which is in line with the other sections related to spreadsheets. Next, three question levels related to trigonometry functions (e.g., RADIAN, SIN, COS) lead to 83\% success for the students. Finally, three question levels covering logarithm functions (e.g., LOG, LN, LOG10) lead to the lowest success of any challenge activity related to spreadsheets, $80 \%$. Finding the formula and value for a number with a base was the third question level in this question set, which may not have been seen previously by the students.

Table 4. Challenge activity success rates for eight sections in 2018. $\mathrm{n}=103$ students.

\begin{tabular}{|l|c|c|c|c|c|}
\hline Section title & Questions & Average & Median & $\begin{array}{c}\text { 1st } \\
\text { quartile }\end{array}$ & $\begin{array}{c}\text { 3rd } \\
\text { quartile }\end{array}$ \\
\hline Spreadsheet basics & 5 & 90 & 100 & 100 & 100 \\
\hline Spreadsheet formulas & 12 & 88 & 100 & 100 & 100 \\
\hline Spreadsheet functions & 7 & 89 & 100 & 100 & 100 \\
\hline Functions: Math and trigonometry & 9 & 84 & 100 & 100 & 100 \\
\hline Functions: Logical & 8 & 86 & 100 & 100 & 100 \\
\hline Sort and filter & 5 & 87 & 100 & 100 & 100 \\
\hline Creating a chart & 7 & 87 & 100 & 100 & 100 \\
\hline Trendlines & 3 & 87 & 100 & 100 & 100 \\
\hline
\end{tabular}

Animation usage

Finally, repetition within the zyBook will be investigated; repetition has documented benefits when learning [27]. With animations, students click to initiate each step, which allows each learner to customize the pace when viewing animations. Click analytics will determine the top 3 most viewed animations and be included in the talk.

\section{Conclusion}

Spreadsheets have become a commodity in recent years, but little training or education for using spreadsheets includes interactivity. Now, an interactive textbook from zyBooks provides students a way interact with spreadsheets and key spreadsheet concepts. Formulas, functions, charts, solver, error, and statistics are covered in this new learning material. By applying cognitive load theory and creating chunks of new content, each section progresses through definitions, question sets, animations, and challenge activities. Students' success reading as well as completing over 100 auto-graded homework problems with randomized numbers and content will be shared. Initial findings include a high reading rate $(90 \%)$ and success on challenge activities $(87 \%)$ for 8 sections and over 50 challenge problems.

\section{Acknowledgments}

The author thanks recent contributions from David C. Smith, Ian Mashburn, Logan Sherman, zyBooks, and countless teaching assistants. This work was completed within the framework of University of Toledo IRB protocol 201808. 


\section{Disclaimer}

One of the authors may receive royalties from sales of the zyBook detailed in this paper.

\section{Bibliography}

1. Hobson, E.H. Getting Students to Read: Fourteen Tips. IDEA Paper \#40 from ideaedu.org. 2004 [cited 2016 December]; Available from:

http://www.ideaedu.org/Portals/0/Uploads/Documents/IDEA\%20Papers/IDEA\%20Paper s/Idea Paper 40.pdf.

2. National Survey of Student Engagement - Question 1c. During the current school year, about how often have you done the following? Come to class without completing readings or assignments. [cited 2016 August]; Available from:

http://nsse.indiana.edu/html/summary tables.cfm.

3. Brost, B.D. and K.A. Bradley, Student Compliance with Assigned Reading: A Case Study. Journal of Scholarship of Teaching and Learning, 2006. 6(2): p. 101-111.

4. Marshall, P., How much, how often? College and Research Libraries, 1974. 35(6): p. 453456.

5. Burchfield, C.M. and T. Sappington, Compliance with required reading assignments. Teaching of Psychology, 2000. 27(1): p. 58-60.

6. Berry, T., L. Cook, N. Hill, and K. Stevens, An Exploratory Analysis of Textbook Usage and Study Habits: Misperceptions and Barriers to Success. College Teaching, 2010. 59(1): p. 31-39. http://dx.doi.org/10.1080/87567555.2010.509376.

7. Yuen, J.S., A. Edgcomb, and F. Vahid. Will Students Earnestly Attempt Learning Questions if Answers are Viewable? in the Proceedings of the ASEE Annual Meeting. 2016. New Orleans, LA.

8. Edgcomb, A., F. Vahid, R. Lysecky, A. Knoesen, R. Amirtharajah, and M.L. Dorf. Student Performance Improvement using Interactive Textbooks: A Three- University Cross-Semester Analysis. in the Proceedings of the ASEE Annual Meeting. 2015. Seattle, WA.

9. Edgcomb, A. and F. Vahid. How Many Points Should Be Awarded for Interactive Textbook Reading Assignments? in the Proceedings of the 45th Annual Frontiers in Education Conference (FIE). 2015. El Paso, TX.

10. Edgcomb, A. and F. Vahid. Effectiveness of Online Textbooks vs. Interactive Web-Native Content. in the Proceedings of the ASEE Annual Conference. 2014. Indianapolis, IN.

11. Carney, A.G., S. Winstead Fry, R.V. Gabriele, and M. Ballard, Reeling in the big fish: Changing pedagogy to encourage the completion of reading assignments. College Teaching, 2008. 56(4): p. 195-201.

12. Landrum, R.E., R.A.R. Gurung, and N. Spann, Assessments of Textbook Usage and the Relationship to Student Course Performance. College Teaching, 2012. 60(1): p. 17-24. http://dx.doi.org/10.1080/87567555.2011.609573.

13. Lepek, D. and M.-O. Coppens. Nature-Inspired Chemical Engineering: Course Development in an Emerging Research Area. in the Proceedings of the ASEE Annual Meeting. 2016. New Orleans, LA. 
14. Mazur, E., G. King, B. Lukoff, and K. Miller. Perusall. 2016 [cited 2016 August]; Available from: http://perusall.com/.

15. Felder, R.M. and R. Brent, Teaching and Learning STEM: A Practical Guide. 2016, San Francisco, CA: Jossey-Bass.

16. Liberatore, M.W., High textbook reading rates when using an interactive textbook for a Material and Energy Balances course. Chemical Engineering Education, 2017. 51(3): p. 109-118.

17. Liberatore, M.W. Reading analytics and student performance when using an interactive textbook for a material and energy balances course. in the Proceedings of the ASEE Annual Conference \& Exposition. 2017. Columbus, OH.

18. Liberatore, M.W., Quantifying reading and online homework completion using an interactive material and energy balances textbook, in AIChE Annual Meeting 2017: Minneapolis, MN.

19. American Enterprise Institute. Price changes selected consumer goods and services 1996-2016. 2016 [cited 2018 January 4]; Available from:

https://www.facebook.com/aei/photos/a.290944073957.147277.44951363957/101552000 85953958/?type $=3 \&$ theater.

20. Lee, C.S., N.J. McNeill, E.P. Douglas, M.E. Koro-Ljungberg, and D.J. Therriault, Indispensable Resource - A Phenomenological Study of Textbook Use in Engineering Problem Solving. Journal of Engineering Education, 2013. 102(2): p. 269-288. http://dx.doi.org/10.1002/jee.20011.

21. Chi, M.T., Active-constructive-interactive: a conceptual framework for differentiating learning activities. Topics in Cognitive Science, 2009. 1(1): p. 73-105. http://dx.doi.org/10.1111/j.1756-8765.2008.01005.x.

22. Chickering, A.W. and Z.F. Gamson, Seven Principles for Good Practice in Undergraduate Education. AAHE Bulletin, 1987: p. 1-7.

23. Freeman, S., S.L. Eddy, M. McDonough, M.K. Smith, N. Okoroafor, H. Jordt, and M.P. Wenderoth, Active learning increases student performance in science, engineering, and mathematics. Proceedings of the National Academy of Sciences, 2014. 111(23): p. 84108415. http://dx.doi.org/10.1073/pnas.1319030111.

24. Zax, D., Learning in 140-Characters Bities. ASEE PRISM, 2009: p. 1-3.

25. Tapscott, D., Grown Up Digital: How the Net Generation is Changing Your World. 2009, New York: McGraw-Hill.

26. Bowen, A.S., D.R. Reid, and M.D. Koretsky, Development of interactive virtual laboratories to help students learn difficult concepts in thermodynamics. Chemical Engineering Education, 2015. 49(4): p. 229-238.

27. Sloan, E.D. and C. Norrgran, A neuroscience perspective on learning. Chemical Engineering Education, 2016. 50(1): p. 29-37.

28. Paas, F., A. Renkl, and J. Sweller, Cognitive load theory: Instructional implications of the interaction between information structures and cognitive architecture. Instructional science, 2004. 32(1): p. 1-8.

29. Wistia. How long should a video be? 2016 [cited 2018 January]; Available from: https://wistia.com/blog/optimal-video-length. 